\title{
Impact of overweight and obesity on the musculoskeletal system using lumbosacral angles
}

\author{
This article was published in the following Dove Press journal: \\ Patient Preference and Adherence \\ 10 March 2016 \\ Number of times this article has been viewed
}

\section{Ndubuisi OC Onyemaechi ${ }^{1,2}$ Godson E Anyanwu ${ }^{3}$ \\ Emmanuel $\mathrm{N}$ Obikili $^{3}$ Okechukwu Onwuasoigwe ${ }^{1,2}$ Okechukwu E Nwankwo',2 \\ 'Department of Surgery, College of Medicine, University of Nigeria Enugu Campus, Enugu, Nigeria; ${ }^{2}$ University of Nigeria Teaching Hospital, Enugu, Nigeria; ${ }^{3}$ Department of Anatomy, College of Medicine, University of Nigeria, Enugu, Nigeria}

Background: Overweight and obesity have been identified as independent risk factors for musculoskeletal disorders. However, the association between obesity and low back pain remains controversial. Little is known about the effects of overweight and obesity on the angles of the lumbosacral spine. The objective of this study was to evaluate the effects of body mass index (BMI) and waist-hip ratio (WHR) on lumbosacral angles.

Methods: The effects of BMI and WHR on the lumbar lordosis angle (LLA), lumbosacral angle (LSA), sacral inclination angle $\left({ }^{\circ}\right)$, and lumbosacral disc angle (LSDA) of 174 overweight and obese subjects (test group) and 126 underweight and normal-weight subjects (control group) were analyzed.

Results: The test group had a significantly higher mean LSA, LLA, sacral inclination angle (SIA), and LSDA $(P=0.001)$. A significant correlation was noted between BMI and LSA $(P=0.001)$, LLA $(P=0.001)$, SIA $(P=0.001)$, and LSDA $(P=0.03)$. There was also a positive relationship between WHR and LSA $(P=0.012)$, LLA $(P=0.009)$, SIA $(P=0.02)$, and LSDA $(P=0.01)$.

Conclusion: There was an increase in lumbosacral angles in individuals with raised BMI and WHR. This may result in biomechanical changes in the lumbosacral spine, which increase the incidence of low back pain.

Keywords: body mass index, waist-hip ratio, lumbosacral angles

\section{Introduction}

Overweight and obesity constitute a growing public health problem and contribute substantially to the burden of chronic medical conditions globally. ${ }^{1}$ There is evidence on the association of obesity with a number of comorbidities including hypertension, diabetes mellitus, dyslipidemia, coronary artery disease, obstructive sleep apnea, menstrual irregularities, and certain types of cancer. ${ }^{2}$ Overweight and obesity have also been shown to be associated with both recurrent and chronic headaches in both adolescents and adults. ${ }^{3}$ Increased body mass index (BMI) has been identified as an independent risk factor for the development of symptoms of musculoskeletal disorders (MSDs). ${ }^{4-6}$ The reported prevalence of osteoarthritis and low back pain (LBP) among obese subjects is $34 \%$ and $22 \%$, respectively. ${ }^{7,8}$ MSDs represent a considerable health problem globally, with LBP as one of the most common MSDs. ${ }^{9}$

The relationship between overweight and obesity and certain MSDs has been well described. Overweight and obesity are known risk factors for osteoarthritis. ${ }^{10}$ They also increase the need for and reduce the health outcomes from joint replacement surgery. ${ }^{11}$

However, the association of obesity with LBP remains controversial. The question whether obesity is a risk factor for LBP has given rise to conflicting reports with no clear causal link between obesity and LBP. A systematic review of the relationship between obesity and LBP revealed inconsistent results. ${ }^{8}$
Correspondence: Ndubuisi OC

Onyemaechi

Department of Surgery, College of Medicine, University of Nigeria Enugu

Campus, PMB 011 29, Enugu, Nigeria

Tel +2348035504767

Email bisionyemaechi@yahoo.com 
The effect of overweight and obesity on the geometric angles of the lumbosacral spine (lumbosacral angles) is of clinical importance. The shape and geometry of the lumbosacral spine have been reported to be of importance in the occurrence of LBP. ${ }^{12,13}$

The impact of overweight and obesity on lumbosacral angles could give an insight into the controversial association between LBP and overweight and obesity.

Many studies have examined the relationship between changes in the angles of the lumbar spine and LBP. The increase in lumbosacral angles was associated with increased risk of LBP. . $^{1415}$

These angles include lumbar lordosis angle (LLA), lumbosacral angle (LSA), sacral inclination angle (SIA), and lumbosacral disc angle (LSDA). Lumbosacral angles could be affected by conditions such as age, posture, race, diseases, and surgery. ${ }^{16-18}$ However, little is known about the effects of overweight and obesity on these angles.

With the global increase in obesity and rising incidence of MSDs, particularly LBP, there is a need to determine the effects that increased loading of the lumbosacral region caused by overweight and obesity may have on the lumbosacral angles. The aim of this study was to evaluate the effects of BMI and waist-hip ratio (WHR) on lumbosacral angles. BMI and WHR are indices of overweight and obesity. ${ }^{19}$ Although BMI assesses general obesity, WHR measures central (truncal) obesity. This relationship may further elucidate the casual link between obesity and LBP.

\section{Materials and methods}

The study was a prospective, cross-sectional study over a 1-year period. The test group comprised 174 subjects (66 obese, 108 overweight), whereas the control group comprised 126 subjects (124 normal weight and two underweight). Their age range was $18-65$ years. All the subjects were black from the Igbo ethnic group of southeastern Nigeria. Only subjects who had attained spinal maturity were enrolled in the study. Subjects who had sustained macrotrauma to the low back region or who had clinically detectable deformity, scoliosis, or kyphosis of the lumbar spine were excluded. Pregnant women and subjects who had had spine surgery or instrumentation were not a part of the study.

The University of Nigeria Teaching Hospital research and ethics committee approved the study protocol. All the subjects provided written informed consent to participate in the study. The demographic profile of the subjects and certain anthropometric measurements were documented using a data entry form. The data collected included age, sex, occupation, weight, height, waist circumference (WC), hip circumstance (HC), BMI, and WHR. X-ray imaging of the lumbosacral vertebrae of the subjects was done in the supine position.

Height was measured using a stadiometer, and weight was measured with a weighing scale after removal of shoes, with light clothing. WC was measured on unclothed abdomen at a point midway between the subcostal margin and the iliac crest, in standing position. ${ }^{20} \mathrm{HC}$ was measured over light clothing at the widest diameter of the hip across the greater trochanters. ${ }^{20}$

BMI was computed as weight $(\mathrm{kg}) /$ height $(\mathrm{m})^{2}$. Subsequently, BMI was classified into five categories: underweight $\leq 18.5 \mathrm{~kg} / \mathrm{m}^{2}$; normal $=18.5-24.9 \mathrm{~kg} / \mathrm{m}^{2}$; overweight $=25-29.9 \mathrm{~kg} / \mathrm{m}^{2}$; obesity $\geq 30 \mathrm{~kg} / \mathrm{m}^{2}$; morbid obesity $>40 \mathrm{~kg} / \mathrm{m}^{2}$ in accordance with the international classification system of the World Health Organization. ${ }^{21}$

WHR is the ratio of WC to $\mathrm{HC}$ and is used to assess central (truncal) obesity. Central obesity is defined as WHR above 0.90 for males and above 0.85 for females. ${ }^{20}$

The lateral projections of the lumbosacral spine radiographs were evaluated. The criteria for normality of the radiographs were as follows:

1. Presence of five lumbar and five sacral vertebrae

2. Progressive increase in vertebral height from $\mathrm{L}_{1}$ to $\mathrm{L}_{5}$

3. Preservation of lumbar lordosis

4. Posterior margins of the lumbar vertebral bodies form a smooth curved line

5. Intervertebral disc spaces increase in thickness from $\mathrm{L}_{1}$ to $\mathrm{L}_{5}$

6. No radiographic evidence of congenital abnormality or disease.

The lumbosacral angles measured using an $\mathrm{x}$-ray viewing box and a transparent goniometer included the following:

1. LSA: the angle between the sacral base and the horizontal plane (Figure 1A)

2. SIA: the angle between a vertical plane and a tangential line to the posterior border of $\mathrm{S}_{\mathrm{I}}$ vertebra (Figure 1B)

3. LSDA: the angle formed by the intersection of two lines drawn through the inferior end plate of $\mathrm{L}_{5}$ and the superior end plate of $\mathrm{S}_{1}$ (Figure 1C)

4. LLA: the angle formed by the intersection of two perpendiculars to lines drawn through the superior end plate of $\mathrm{L}_{1}$ and the inferior end plate of $\mathrm{L}_{5}$ (Figure 1D).

Statistical analysis was done using SPSS version 17.0 (SPSS Inc., Chicago IL, USA). Prior to analysis, we verified the normality of continuous variables distributions and tested the homogeneity of their variances with the Levene's test. Continuous variables were expressed as mean and standard deviation. Comparison of means of both sets of data was done 
A

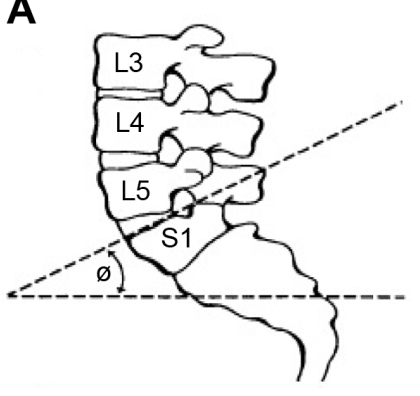

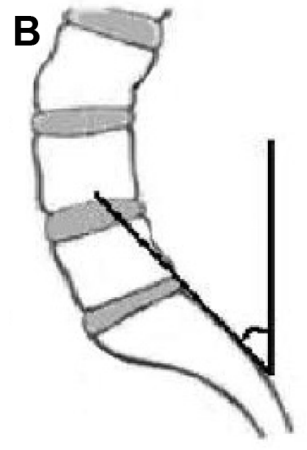

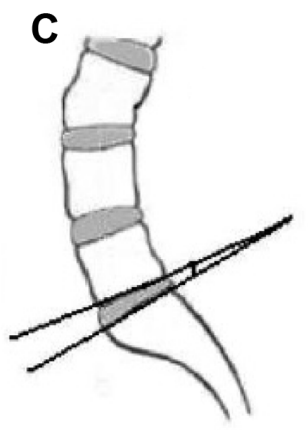

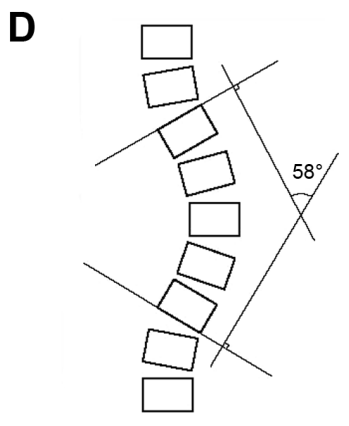

Figure I Measurement of geometric angles of the lumbosacral spine.

Notes: Lumbosacral angle (A). Sacral inclination angle (B). Lumbosacral disc angle (C). Lumbar lordosis angle (D).

using the Student's $t$-test for independent samples. Statistical significance was set at $P$-value $<0.05$.

\section{Results}

The data of the 300 subjects who met the inclusion criteria were analyzed. The mean age of the test group was $46.5 \pm 13.6$ years, whereas that of the control group was $48 \pm 12$ years. The age distribution of the subjects is shown in Table 1. There were 84 (48.3\%) male and $90(51.7 \%)$ female subjects in the test group. In the control group, there were $60(47.6 \%)$ male and $66(52.4 \%)$ female subjects. The distribution of the subjects by BMI is shown in Table 2 .

A total of 130 (43.3\%) subjects had a WHR of $<0.90$, $140(46.7 \%)$ subjects had a WHR of $0.90-0.95$, and $30(10 \%)$ subjects had a WHR of 0.96-1.0 (Table 3). In total, 56 (35.9\%) of the female subjects had a WHR of $<0.90$, and $100(64.1 \%)$ had a WHR of $>0.90$. While 74 (51.4\%) male subjects had a WHR $<0.90,70(48.6 \%)$ had a WHR $>0.90$.

The mean LSA of the test group was $39.2^{\circ} \pm 9.2^{\circ}$ and that of the control group was $34.5^{\circ} \pm 8.9^{\circ}$; the difference was statistically significant $(P=0.001)$. The mean LLA of the test group was $42.8^{\circ} \pm 11.2^{\circ}$ and that of the control group was $37.2^{\circ} \pm 9.8^{\circ}$ $(P=0.001)$. The mean SIA of the test group was $40.4^{\circ} \pm 8.2^{\circ}$ and that of the control group was $36.3^{\circ} \pm 7.5^{\circ}(P=0.001)$. The mean SIA of the male subjects was $36.6^{\circ} \pm 8.3^{\circ}$ and that of the female subjects was $39.8^{\circ} \pm 9.3^{\circ}$. The difference among the sexes was statistically significant in both the groups $(P=0.03)$.

Table I Frequency distribution of subjects by age groups

\begin{tabular}{lll}
\hline Age groups (years) & Frequency & Percentage \\
\hline $15-24$ & 16 & 5.3 \\
$25-34$ & 41 & 13.7 \\
$35-44$ & 64 & 21.3 \\
$45-54$ & 68 & 22.7 \\
$55-64$ & 111 & 37.0 \\
Total & 300 & 100 \\
\hline
\end{tabular}

The mean LSDA of the test group was $15.0^{\circ} \pm 3.4^{\circ}$ and that of the control group was $13.5^{\circ} \pm 4.5^{\circ}(P=0.01)$. Table 4 shows the distribution of BMI of subjects by sex and the comparison of means of the lumbosacral angles based on BMI.

A significant correlation was noted between BMI and all the lumbosacral angles in both males and females: LSA $(P=0.001)$, LLA $(P=0.001)$, SIA $(P=0.001)$, and LSDA $(P=0.03)$. There was also a positive relationship between WHR and LSA $(P=0.012)$, LLA $(P=0.009)$, SIA $(P=0.02)$, and LSDA $(P=0.01)$ in both the sexes. Table 5 shows the distribution of WHR of subjects by sex and the comparison of the means of the lumbosacral angles based on WHR.

\section{Discussion}

The clinical significance of lumbosacral angles lies majorly in their association with LBP, ${ }^{14,15,18}$ design of spinal implants and instrumentations, ${ }^{22}$ and spine surgery. ${ }^{23}$

We noted a positive association between LSA and BMI $(P=0.001)$. WHR and LSA also had a significant correlation in both the groups $(P=0.001)$. The subjects with increased BMI and WHR had significantly higher LSA than the subjects with normal BMI and WHR. Braunaugh et $\mathrm{a}^{24}$ also noted significant correlation among BMI, WHR, and LSA. In subjects with increased BMI, particularly those with truncal obesity, the weight of the trunk may displace the base of the sacrum anteriorly, thus increasing LSA. Thus, overweight

Table 2 Distribution of subjects by BMI

\begin{tabular}{lll}
\hline BMI & Frequency & Percentage \\
\hline Underweight & 2 & 0.7 \\
Normal & 124 & 41.3 \\
Overweight & 108 & 36.0 \\
Obese & 66 & 22 \\
Total & 300 & 100 \\
\hline
\end{tabular}

Notes: $<18.5 \mathrm{~kg} / \mathrm{m}^{2}$, underweight; $18.5-24.9 \mathrm{~kg} / \mathrm{m}^{2}$, normal; $25-29.9 \mathrm{~kg} / \mathrm{m}^{2}$, overweight; $>30 \mathrm{~kg} / \mathrm{m}^{2}$, obese; $>40 \mathrm{~kg} / \mathrm{m}^{2}$, morbid obesity.

Abbreviation: BMl, body mass index. 
Table 3 Distribution of subjects by waist-hip ratio

\begin{tabular}{lll}
\hline Waist-hip ratio & Frequency & Percentage \\
\hline$<0.90$ & 130 & 43.3 \\
$0.90-0.95$ & 140 & 46.7 \\
$>0.96$ & 30 & 10 \\
Total & 300 & 100 \\
\hline
\end{tabular}

and obesity seem to induce an increase in anterior pelvic tilt. The increased anterior pelvic tilt induces a greater flexion of the sacroiliac joints, and therefore a higher torque on $\mathrm{L}_{5}-\mathrm{S}_{1}$ joints and discs. This possibly increases shear forces at this level and overloads the disc, thus increasing the risk of disc degeneration. ${ }^{25}$ Therefore, increased LSA as seen in obese and overweight individuals may increase the risk of LBP.

We observed higher LLAs in obese and overweight subjects. This may be due to increased mechanical loading of the lumbar spine with consequent exaggeration of LLA. This is similar to the postural changes observed in pregnant women. ${ }^{26}$ The consequent biomechanical changes may produce higher compressive force or increase shear on the lumbar spine structures, resulting in an increased incidence of mechanical LBP in individuals with raised BMI and truncal obesity. Many studies have already reported positive associations between increased lumbar lordosis and LBP. ${ }^{15,27}$ These effects of increased BMI and WHR on LLA may increase the incidence of LBP among overweight and obese individuals. There was no significant variation in the mean lordosis angles between the male and female subjects in this study. This is in contrast with studies that reported greater lordotic angles in women. ${ }^{18,28}$ This contrast may be due to racial differences in the study populations.

The overweight and obese subjects had significantly higher SIA than the controls. The female subjects also had a higher SIA $(P=0.03)$. These are similar to the studies by Fernand and Fox, ${ }^{13}$ Caglayan et al, ${ }^{15}$ and Evcik and Yucel. ${ }^{29}$ Caglayan et $\mathrm{al}^{15}$ also observed that SIA and BMI were higher in female patients with LBP in a control study. The position of the sacrum in the pelvis affects the pelvic inlet and outlet diameters. Therefore, a more inclined sacrum creates a larger pelvic outlet diameter in females, which is important during childbirth. This may explain the higher SIA in females. Axial loading of the sacral base in overweight and obese individuals may be responsible for the increased sacral inclination noted in this group. Some studies ${ }^{15,29}$ have reported an association between increased SIA and LBP. Evcik and Yucel ${ }^{29}$ reported that SIA was larger in patients with chronic LBP, with a positive relationship between this angle and maximal range of lumbar extension in both males and females. Increased SIA has been associated with spondylolisthesis and isthmic pathologies. ${ }^{29}$ Consequently, this may cause facet joint problems and spinal stenosis, resulting in increased incidence of LBP among individuals with high BMI.

Our study showed a significant correlation between BMI, WHR, and LSDA. This suggests that individuals with increased BMI and WHR have higher LSDA. The increased sacral inclination noted in the test group may explain the higher LSDA values as the sacral inclination directly affects LSDA. An increase in LSDA is associated with an increased incidence of facet syndrome in subjects with LBP. ${ }^{30,31}$ LSDA $>15^{\circ}$ has been reported to increase the compressive and shearing forces at $\mathrm{L}_{5} / \mathrm{S}_{1}$ facet joint. ${ }^{30,31}$

The facet joints in the lumbar vertebrae are not adapted for weight bearing but rather for preventing excessive rotation. Therefore, minor biomechanical changes in the lumbosacral segment will result in exaggerated shearing and compressive forces at the lumbosacral facet joints, giving rise to mechanical LBP. ${ }^{30}$ The positive association noted among BMI, WHR, and LSDA therefore suggests that overweight and obese individuals, particularly those with truncal obesity, may have an increased risk of facet syndrome and mechanical LBP.

A major limitation of the study is that it was conducted on only one ethnic group in Nigeria. Large multi-ethnic

Table 4 Comparison of mean lumbosacral angles based on BMI of subjects

\begin{tabular}{|c|c|c|c|c|c|c|c|c|}
\hline \multirow[t]{3}{*}{ Lumbosacral angles } & \multicolumn{4}{|l|}{ Male } & \multicolumn{4}{|l|}{ Female } \\
\hline & $\begin{array}{l}\text { Control group } \\
\text { BMI }(n=60) \\
\end{array}$ & $\begin{array}{l}\text { Test group } \\
\text { BMI }(n=84) \\
\end{array}$ & $t$ & $P$-value & $\begin{array}{l}\text { Control group } \\
\text { BMI }(n=66) \\
\end{array}$ & $\begin{array}{l}\text { Test group } \\
\text { BMI }(n=90) \\
\end{array}$ & $t$ & $P$-value \\
\hline & Mean \pm SD & Mean \pm SD & & & Mean \pm SD & Mean \pm SD & & \\
\hline LSA & $34.5 \pm 7.0$ & $39.5 \pm 9.6$ & -3.47 & 0.001 & $34.7 \pm 6.7$ & $40.1 \pm 10.1$ & -3.59 & 0.001 \\
\hline LLA & $37.3 \pm 9.5$ & $41.2 \pm 11.9$ & -2.14 & 0.03 & $37.4 \pm 8.0$ & $43.1 \pm 12.1$ & -3.03 & 0.003 \\
\hline SIA & $35.9 \pm 8.3$ & $39.3 \pm 12.1$ & -2.02 & 0.03 & $37.1 \pm 8.3$ & $41.9 \pm 9.0$ & -3.22 & 0.001 \\
\hline LSDA & $13.6 \pm 3.3$ & $15.1 \pm 3.1$ & -2.32 & 0.01 & $13.5 \pm 3.1$ & $14.7 \pm 3.4$ & -2.24 & 0.02 \\
\hline
\end{tabular}

Abbreviations: BMI, body mass index; SD, standard deviation; LSA, lumbosacral angle; LLA, lumbar lordosis angle; SIA, sacral inclination angle; LSDA, lumbosacral disc angle. 
Table 5 Comparison of mean lumbosacral angles based on WHR of subjects

\begin{tabular}{|c|c|c|c|c|c|c|c|c|}
\hline \multirow[t]{3}{*}{ Lumbosacral angles } & \multicolumn{4}{|l|}{ Male } & \multicolumn{4}{|l|}{ Female } \\
\hline & \multirow{2}{*}{$\begin{array}{l}\text { WHR }<0.90 \\
(n=74) \\
\text { Mean } \pm \text { SD }\end{array}$} & \multirow{2}{*}{$\begin{array}{l}\text { WHR }>0.90 \\
(n=70) \\
\text { Mean } \pm \text { SD }\end{array}$} & \multirow[t]{2}{*}{$t$} & \multirow[t]{2}{*}{$P$-value } & \multirow{2}{*}{$\begin{array}{l}\text { WHR }<0.90 \\
(n=56) \\
\text { Mean } \pm \text { SD }\end{array}$} & \multirow{2}{*}{$\begin{array}{l}\text { WHR }>0.90 \\
(n=100) \\
\text { Mean } \pm \text { SD }\end{array}$} & \multirow[t]{2}{*}{$t$} & \multirow[t]{2}{*}{$P$-value } \\
\hline & & & & & & & & \\
\hline LSA & $35.5 \pm 6.5$ & $39.0 \pm 10.0$ & -2.21 & 0.03 & $37.8 \pm 9.6$ & $41.6 \pm 10.2$ & -2.35 & 0.003 \\
\hline LLA & $37.5 \pm 8.7$ & $41.8 \pm 11.0$ & -2.36 & 0.02 & $38.5 \pm 10.1$ & $43.4 \pm 12.5$ & -3.12 & 0.001 \\
\hline SIA & $37.6 \pm 8.1$ & $40.8 \pm 8.7$ & -2.13 & 0.04 & $38.8 \pm 8.4$ & $43.1 \pm 9.3$ & -2.81 & 0.002 \\
\hline LSDA & $13.7 \pm 2.8$ & $15.3 \pm 3.1$ & -2.86 & 0.005 & $13.7 \pm 2.7$ & $15.2 \pm 3.1$ & -2.72 & 0.005 \\
\hline
\end{tabular}

Abbreviations: WHR, waist-hip ratio; SD, standard deviation; LSA, lumbosacral angle; LLA, lumbar lordosis angle; SIA, sacral inclination angle; LSDA, lumbosacral disc angle.

and multi-racial studies will be needed to validate our findings. The sample size in this study was sufficient and the methodology was scientific; therefore, the results are generalizable to other black ethnic groups.

\section{Conclusion}

In this study, subjects with raised BMI and WHR had significantly higher mean LSA, LLA, SIA, and LSDA. These angles also increased as the BMI and WHR of the subjects increased. The increase in lumbosacral angles seen in these individuals may result in biomechanical changes in the lumbosacral spine, which may increase the incidence of LBP. Our study supports the reports that overweight and obesity are potential risk factors for LBP. The causal link between obesity and LBP has been further elucidated by this study. We recommend measurements of lumbosacral angles in clinical evaluation of patients with LBP.

\section{Disclosure}

The authors report no conflicts of interest in this work.

\section{References}

1. Haslam DW, James WP. Obesity. Lancet. 2005;366(9492):1197-1209.

2. Pi-Sunyer FX. Comorbidities of overweight and obesity: current evidence and research issues. Med Sci Sports Exerc. 1999;31(11 suppl): S602-S608.

3. Scher AI, Stewart WF, Ricci JA, Lipton RB. Factors associated with the onset and remission of chronic daily headache in a population-based study. Pain. 2003;106:81-89.

4. Nilsen TIL, Holtermann A, Mork PJ. Physical exercise, body mass index and risk of chronic pain in the low back and neck/shoulders: longitudinal data from the Nord-Trondelag Health Study. Am J Epidemiol. 2011;174: 267-273.

5. Blagojevic M, Jinks C, Jeffery A, Jordan KP. Risk factors for onset of osteoarthritis of the knee in older adults: a systematic review and metaanalysis. Osteoarthritis Cartilage. 2010;18:24-33.

6. Viester L, Verhagen E, Hengel KM, Koppes L, Van der Beek A, Bonger P. The relation between body mass index and musculoskeletal symptoms in the working population. BMC Musculoskelet Disord. 2013;14:238.

7. Mellin G, Harkappa K, Vanharanta H, Hupli M, Heinonen R, Jarvikoski A. Outcome of a multimodal treatment including intensive physical training of patients with chronic low back pain. Spine. 1993;18(7):825-829.
8. Leboeuf-Yde C. Body weight and low back pain: a systematic literature review of 56 journal articles reporting on 65 epidemiologic studies. Spine. 2000;25:226-237.

9. Picavet HSJ, Schouten JS. Musculoskeletal pain in the Netherlands: prevalences, consequences and risk groups, the DMC (3) study. Pain. 2003;102:167-178.

10. Pottie P, Presle N, Terlain B, Netter P, Mainard D, Berenbaum F. Obesity and osteoarthritis: more complex than predicted. Am Rheum Dis. 2006;65:1403-1405.

11. Anandacoomarasamy A, Fransen M, March L. Obesity and musculoskeletal system. Curr Opin Rheumatol. 2009;21(1):71-77.

12. Lord MJ, Small JM, Dinsay JM, Watkins RG. Lumbar lordosis. Effects of sitting and standing. Spine. 1997;22:2571-2574.

13. Fernand R, Fox DE. Evaluation of Lumbar lordosis: a prospective and retrospective study. Spine. 1985;10:799-803.

14. Sarikaya S, Ozdolap S, Gumustas S, Koc U. Low back pain and lumbar angles in Turkish coal miners. Am J Ind Med. 2007;50:92-96.

15. Caglayan M, Tacar O, Demirant A, et al. Effects of lumbosacral angles on development of low back pain. J Musculoskelet Pain. 2014; 12(3):251-255.

16. Gelb DE, Lanke LG, Bridwell KH, Blanke K, McEnery KW. An analysis of sagittal spine alignment in 100 asymptomatic middle aged and older volunteers. Spine. 1995;20:1351-1358.

17. Azar MS, Talebpour F, Alaee A, et al. Association of low back pain with lumbar lordosis and lumbosacral angle. JMazand University Med Sci. 2009;20(75):9-15.

18. Amonoo-Kuofi HS. Changes in the lumbosacral angle, sacral inclination and lumbar spine during ageing. Acta Anatomica. 1992;145(4) 373-377.

19. Akpinar E, Bashan I, Bozdemir N, Saatci E. Which is the best anthropometric technique to identify obesity: body mass index, waist circumference or waist-hip ratio. Coll Antropol. 2007;31(2):387-393.

20. WHO. Waist circumference and waist-hip ratio: report of a WHO expert consultation. Geneva: World Health Organisation (WHO); 2008: $1-47$.

21. [No authors listed]. Obesity: preventing and managing the global epidemic. Report of a WHO consultation. World Health Organ Tech Rep Ser. 2000;894(i-xii):1-253.

22. Zhou SH, McCarthy ID, McGregor AH, Coombs RR, Hughes SP. Geometric dimensions of the lower lumbar vertebrae - analysis of data from digitized CT images. Eur Spine J. 2009;9:242-248.

23. Swank SM, Mauri TM, Brown JC. The lumbar lordosis below Harrington instrumentation for scoliosis. Spine. 1990;15:181-186.

24. Brunaugh J, Jansen D, Levin J, Lippy J. A pilot study of the relationship between body mass index, waist to hip ratio and sacral base angle [dissertation]. Chesterfield: Logan College of Chiropractic; 2002:1-12.

25. Liuke M, Solovieva S, Lamminen A, et al. Disc degeneration of the spine in relation to overweight. Int J Obes. 2005;29(8):903-908.

26. Larsson UE. Influence of weight loss on pain, perceived disability functional limitations in obese woman. Int J Obes Relat Metab Disord. 2004;28:269-277. 
27. Korovessis PG, Stamatakis MV, Baikousis AG. Reciprocal angulation of vertebral bodies in the sagittal plane in an asymptomatic Greek population. Spine. 1998;23(6):700-705.

28. Murrie VL, Dixon AK, Holingworth W, Wilson H, Doyle TA. Lumbar lordosis: study of patients with and without low back pain. Clin Anat. 2003; 16(2):144-147.

29. Evcik D, Yucel A. Lumbar lordosis in acute and chronic low back pain patients. Rheumatol Int. 2003;23:163-165.
30. Cox JM. Low Back Pain: Mechanisms, Diagnosis and Treatment. 6th ed. Baltimore: Williams and Wilkins; 1999:480-512.

31. Yochum TR, Rowe LJ. Essentials of Skeletal Radiology. Vol 1. 3rd ed. Philadelphia: Williams and Wilkins; 2005:53-70.

\section{Publish your work in this journal}

Patient Preference and Adherence is an international, peer-reviewed, open access journal that focuses on the growing importance of patient preference and adherence throughout the therapeutic continuum. Patient satisfaction, acceptability, quality of life, compliance, persistence and their role in developing new therapeutic modalities and compounds to optimize clinical outcomes for existing disease states are major areas of interest for the journal. This journal has been accepted for indexing on PubMed Central. The manuscript management system is completely online and includes a very quick and fair peer-review system, which is all easy to use. Visit http://www dovepress.com/testimonials.php to read real quotes from published authors.

Submit your manuscript here: http://www.dovepress.com/patient-preference-and-adherence-journal 